\title{
Ensino da Geografia na Educação Básica
}

\author{
Teaching Geography in Basic Education \\ Enseñanza de la Geografía en la Educación Básica
}

Recebido: 25/08/2021 | Revisado: 03/09/2021 | Aceito: 07/09/2021 | Publicado: 09/09/2021

\author{
Maria Lidijanne Cardoso Zuza \\ ORCID: https://orcid.org/0000-0002-6524-5661 \\ Universidade Federal de Alfenas, Brasil \\ E-mail: maria_lidejane@hotmail.com
}

\begin{abstract}
Resumo
A abordagem da geografia enquanto disciplina escolar tem se apresentado de forma desafiadora para uma grande maioria de seus respectivos professores, pois ainda se percebe a prática de um modelo pedagógico tradicional, descritivo e memorístico desta ciência nas escolas do país. Dentro dessa perspectiva, foi realizado este trabalho de revisão, tendo como Objetivo Geral analisar o ensino da Geografia na educação básica. Sua metodologia foi realizada por meio da revisão de literatura, com levantamentos bibliográficos utilizando livros, artigos e trabalhos de conclusão de curso, sendo um estudo descritivo com abordagem qualitativa. Teve como amostra, Artigos de principais revistas como Revista Rene, SciELO, dissertações de mestrado da Universidades Federais, trabalhos científicos publicados no Plano Pedagógico disponibilizado na BNCC. Utilizou-se de artigos publicados em revistas, livros de Ensino e dissertações da língua portuguesa e inglesa, publicados do ano de 1998 até os dias de hoje. Como procedimento de estudo, inicialmente foi feito um levantamento de dados dos artigos, livros e dissertações, selecionados a partir de palavras chaves como Ensino e Geografia. Como conclusão, a Geografia vem acompanhando a evolução do homem, a partir do momento em que ela surgiu como disciplina escolar. Com as transformações ocorridas no mundo inteiro, a Geografia buscou acompanhar essas tendências, apesar de estar ainda muito atrelada aos moldes tradicionais enquanto disciplina. Assim, necessita-se estar sempre em debate e sob-reflexões por parte daqueles que a estudam. Esta pesquisa procurou fazer um trabalho de análise metodológica do ensino de Geografia em escolas de ensino básico.
\end{abstract}

Palavras-chave: Ensino; Geografia; Aprendizagem.

\begin{abstract}
An approach to geography in a school discipline subject was presented in a challenging way for a large majority of their respective teachers, pois also seen the practice of a traditional pedagogical model, descriptive and memorable, outstanding in schools in the country. From this perspective, this revision work was carried out, having as a general objective to analyze or teach Geography in basic education. Its methodology was carried out by means of a literature review, with bibliographic surveys using books, articles and work on completion of the course, being a descriptive study with a qualitative approach. You have as a sample, Articles from main magazines such as Revista Rene, SciELO, lectures on the teaching of Federal Universities, scientific papers published in the Pedagogical Plan available at BNCC. Use of articles published in magazines, books of Ensino e dissertações da lngua Portuguese and English, published in 1998 at the days of the leaf. As a study procedure, initially a survey was made of two articles, books and lectures, selected from chave words such as Ensino e Geografia. As a conclusion, Geography is accompanied by the evolution of home, from the moment it emerged as a school discipline. As transformations or runs in the world inside, Geography seeks to accompany these trends, despite being very daring years traditional molds in such a discipline. Also, it is always necessary to be in debate and over-reflection on the part of those who are studying. This research sought to carry out a work of methodological analysis of the ensino of Geography in schools of basic ensino.
\end{abstract}

Keywords: Teaching; Geography; Learning.

\section{Resumen}

El enfoque de la geografía como asignatura escolar ha sido un desafío para una gran mayoría de sus respectivos profesores, ya que aún se percibe la práctica de un modelo pedagógico tradicional, descriptivo y conmemorativo de esta ciencia en las escuelas de todo el país. En esta perspectiva, se realizó este trabajo de revisión, con el objetivo general de analizar la enseñanza de la geografía en la educación básica. Su metodología se llevó a cabo mediante revisión de literatura, con levantamientos bibliográficos utilizando libros, artículos y trabajos de conclusión de curso, siendo un estudio descriptivo con enfoque cualitativo. La muestra incluyó artículos de importantes revistas como Revista Rene, SciELO, disertaciones de maestría de Universidades Federales, trabajos científicos publicados en el Plan Pedagógico disponible en BNCC. Se utilizaron artículos publicados en revistas, libros de texto y disertaciones en portugués e inglés, publicados desde 1998 hasta la actualidad. Como procedimiento de estudio, inicialmente se realizó un relevamiento de datos de artículos, libros y disertaciones, seleccionados entre palabras clave como Docencia y Geografía. En conclusión, la Geografía ha ido siguiendo la evolución del hombre, desde que surgió como asignatura 
escolar. Con las transformaciones que se han producido en todo el mundo, la Geografía ha buscado seguir estas tendencias, aunque todavía está muy ligada a los moldes tradicionales como disciplina. Por eso, siempre es necesario estar en debate y poca reflexión por parte de quienes lo estudian. Esta investigación buscó realizar un trabajo de análisis metodológico de la enseñanza de la Geografía en las escuelas primarias.

Palabras clave: Ensino; Geography; Apprenticeship.

\section{Introdução}

A abordagem da geografia enquanto disciplina escolar tem se apresentado de forma desafiadora para uma grande maioria de seus respectivos professores, pois ainda se percebe a prática de um modelo pedagógico tradicional, descritivo e memorístico desta ciência nas escolas do país (Oliveira et al., 2019).

Entretanto, tudo isso só é possível a partir da ação imprescindível do professor. Sabe-se que não existe uma receita infalível de metodologias para se desenvolver aulas interessantes que atraiam os alunos, todos os dias do ano. Não obstante, é preciso também que sejam desenvolvidas relações de afeto, simpatia e entusiasmo entre educador e educando, como base para a criação de um clima propício à aprendizagem. Infere-se criatividade e sensibilidade do professor para a condução do laborioso processo de transformar o conhecimento de senso comum em saber científico que, então incorporado pelo aluno, permitir-lhe-á ressignificar o mundo (Dezotti \& Ortiz, 2010).

Como ciência moderna, a geografia surge como elemento de reconhecimento, conquista e domínio territorial, ao mesmo tempo em que se configura como estratégia de construção e fortalecimento de certa identidade nacional. Vale ressaltar que este é também um dos fundamentos da Geografia que se fazia no mundo greco-romano, uma geografia ligada à necessidade de expansão, organização e controle territorial (Girotto, 2010).

Nesta conjuntura, surge o papel do professor (a) da disciplina de geografia, o qual deve buscar uma verdadeira aproximação entre as várias geografias estudadas e o vivido do aluno. Esta necessidade decorre do fato de que "a compreensão do espaço geográfico pressupõe o desenvolvimento do olhar espacial, especialidade da Geografia, o qual proporciona as condições para a efetiva aprendizagem geográfica, valorizando o movimento, a contextualização e o cotidiano" (Tonini, 2011, p. 24).

Diante do exposto decorre a importância do ensino na geografia na educação básica. O presente estudo estabelece a seguinte questão problematizadora: Como o ensino da geografia na educação básica pode beneficiar o aluno em termos pedagógicos? Dessa forma, a pesquisa propõe uma proporção de escolhas, onde o pesquisador deve estar atento a todos os estudos que existam e se faça referência a seu tema de estudo para que assim possa atender aos anseios dos seus futuros leitores. Sendo assim, objetivou-se analisar o ensino da Geografia na educação básica utilizando métodos exploratórios e bibliográficos.

A construção do presente texto é estruturada diante das seguintes partes: na primeira, vem à introdução onde fala e expõe sobre a importância do ensino da Geografia na Educação Básica. Na segunda parte, vem o desenvolvimento que apresenta os seguintes tópicos: A importância da pesquisa na geografia para a sociedade; e a Percepção da relação formação do professor e o ensino da Geografia.

\section{Metodologia}

Caracterização do Estudo: pesquisa foi realizada por meio da revisão de literatura, com levantamentos bibliográficos utilizando livros, artigos e trabalhos de conclusão de curso, sendo um estudo descritivo com abordagem qualitativa. Segundo Prodanov e Freitas (2013), "a pesquisa descritiva é quando o pesquisador não interfere nos fatos, ele apenas observa, caracteriza de acordo com as causas, relações com outros fatos e registra esses dados". 
De acordo com Richardson et al (2012), o método qualitativo não é utilizado para numerar ou medir unidades. Este método visa descrever a complexidade de um problema, analisando variáveis e classificando processos dinâmicos dos grupos sociais, contribuindo para um processo de mudança do grupo e possibilitando o melhor entendimento e comportamento dos indivíduos.

Amostra: Artigos de principais revistas como Revista Rene, SciELO, dissertações de mestrado da Universidades Federais, trabalhos científicos publicados no Plano Pedagógico disponibilizado na BNCC.

Critérios de Inclusão: Utilizou-se de artigos publicados em revistas, livros de Ensino e dissertações da língua portuguesa e inglesa, publicados do ano de 1998 até os dias de hoje. Critérios para seleção destes artigos, livros e dissertações serão utilizados, como o que houver maior coerência, coincidência e que acrescentará conhecimento sobre o tema escolhido, excluindo assim aqueles que não estiverem coerentes e que não acrescentarão conhecimento para elaboração do trabalho.

Procedimentos do estudo: Inicialmente foi feito um levantamento de dados dos artigos, livros e dissertações, selecionados a partir de palavras chaves como Ensino e Geografia. Após levantamento desses artigos, foram analisados e separados com critério de coerência com o tema escolhido.

Levando em consideração o objetivo que foi traçado, a pesquisa tem um caráter exploratório, uma vez que, esta tem como base assuntos já discutidos em nossa sociedade e estudadas por diversos especialistas no assunto.

Foi realizado ainda o procedimento técnico de pesquisa bibliográfica o qual estará sendo desenvolvido através da leitura e da análise de livros, artigos que tratam do tema abordado, tendo como referencias os seguintes autores citado no decorrer do trabalho.

\section{Resultados e Discussão}

\subsection{A importância da pesquisa na geografia para a sociedade}

A Geografia tem como objetivo principal entender a dinâmica do espaço para auxiliar no planejamento das ações do homem sobre ele. Entender as formas de relevo, os fenômenos climáticos, as composições sociais, os hábitos humanos nos diferentes lugares são imprescindíveis para a manutenção da vida em sociedade.

Essa ciência foi e ainda é muito utilizada para fins militares, uma vez que se faz extremamente necessário o conhecimento sobre um determinado território para a sua ocupação ou para se adquirir vantagens em uma batalha ou guerra. Por conta disso, no ano de 1977, o geógrafo Yves Lacoste escreveu uma obra intitulada A Geografia serve - antes de mais nada - para fazer a Guerra, reafirmando a utilidade militar e política da Geografia, bem como o seu caráter extremamente ideológico de manutenção e consolidação do sistema capitalista.

Segundo Bagno (2001, p. 18) há também a pesquisa científica, esta que é uma "investigação feita com o objetivo expresso de obter conhecimento específico e estruturado sobre um assunto preciso", ou seja, é uma pesquisa realizada com embasamentos teóricos, que tende a ser um estudo mais aprofundado obtendo um objetivo ou tema principal a ser explanado.

$\mathrm{Na}$ atualidade nota-se que a maioria dos cientistas surgem, através da pesquisa ou projeto enriquecendo o modo de educar que segundo Paro (2002):

"É uma maneira de oferecer cultura ao ser humano, ou seja, mostrar a realidade e seus aspectos socioculturais, no qual, o ato da pesquisa/projeto se antecipará na escola regular e deixará de ser enraizado somente no ensino superior" (Paro, 2002).

A respeito dessa Geografia estudada nas universidades e sua articulação com a formação do docente, tentaremos aqui discorrer algumas palavras afim de melhor sintetizar o papel do curso de Geografia na formação do professor. 
Apesar da extrema importância da profissão de professor, visto que é este quem "proporcionará" as oportunidades de desenvolvimento futuro da sociedade e da economia por meio de seu êxito no processo de aprendizagem para com seus alunos, infelizmente os cursos de licenciatura carregam um estereótipo de cursos fracos.

A profissão, professor, é subjulgada, geralmente somos vistos como profissionais despreparados, desatualizados etc., vê-se que até mesmo pelos olhares das próprias universidades, os cursos de licenciaturas não são priorizados.

O problema que surge é que tanto por parte das universidades públicas quanto por parte das instituições particulares a formação dos professores não é tratada com a devida importância, sempre há uma maior atenção aos cursos relacionados com as áreas tecnológicas.

A respeito da baixa qualidade dos cursos em instituições privadas Pontuschka et al. (2009), ponderam que é "fato reconhecido a baixa qualidade desses cursos, tendo em vista que, na maioria das instituições, a organização curricular seguiu, durante anos, o modelo das "pequenas" licenciaturas".

$\mathrm{Na}$ escola é fundamental mediarmos essas informações que chegam atualmente de maneira muito veloz, assim consequentemente criando uma "cultura global". É uma total análise do homem com o espaço, e como há uma diferença enorme até mesmo numa simples sala de aula de um indivíduo para outro, precisa-se ter uma maneira adaptável para cada realidade apresentada.

\subsection{Ensino de geografia, escola e cidadania}

O bem estar social é almejado pelos mais diferentes grupos sociais. Porém, para torná-lo realidade é preciso e uma luta intensa em busca da cidadania. Assim, entendemos a cidadania como "um conjunto de direitos civis, políticos e sociais que todo homem tem que conquistar para viver em sociedade, num determinado lugar". Esses direitos vêm sendo conquistados e ampliados pelos homens no decorrer dos anos, em virtude de novas necessidades surgirem em cada momento histórico.

Nesse processo renovador a escola pode contribuir bastante, movendo ações que despertem o censo crítico do aluno, levando-o a compreender, discutir e ter acesso á cidadania (Andrade, 2018). O desenvolvimento de maneiras mais eficazes de pensar no ensino atual é muito importante. Para Laurín (Ortega Rocha \& Pagès Blanch, 2017), é importante distinguir corretamente no processo de ensino e aprendizagem da geografia as relações entre pensamento e conteúdo; entre raciocínio, conhecimento e experiência, a fim de favorecer a ação social (Moreno-Hernández et al., 2021).

Contudo, percebe-se que os assuntos referentes á cidadania ainda estão restritos á universidade, tornando-se assim distantes das aulas de Geografia dos níveis fundamental e médio. Considerando, dessa forma, a escola o palco para a manifestação de conhecimentos, devemos então buscar, ampliar e exercer também através dela a cidadania para assim podermos discuti-la, não só nas aulas de Geografia, assim como nas outras disciplinas ou em qualquer eventualidade em que convenha a discussão (Sousa et al., 2004).

Percebe-se nas instituições de ensino grande preocupação dos docentes na prática em sala de aula, de mudar esta realidade através das relações diárias, pois a escola tem como função ensinar, promover acesso ao conhecimento para que todos, especialmente, os alunos das classes menos favorecidas possam ter o direito ao exercício da cidadania. Portanto, a escola vem passando por modificações necessárias para acompanhar a evolução tecnológica que interfere no processo de ensino aprendizagem dos alunos.

O aluno, geralmente, está preocupado em que faça valer o seu direito, sem a responsabilidade como: usar o celular na sala de aula, sair da sala em horário de aula, ou seja, significa apenas ter acesso aos seus direitos e não aos deveres.

De acordo com Castro Giovanni (1998): 
"Uma educação voltada para a cidadania é necessária, pois é pela educação que as comunidades expressam sua cultura e também terão capacidade de defendê-la quando outros valores forem tomados como certos e universais" (Giovanni, 1998).

As práticas pedagógicas são, portanto, de extrema importância para o aprendizado, visto que ela pode ser responsável pela motivação do aluno. Trazer para a sala de aula assuntos diários, gerar debates acerca do conteúdo pode envolvê-lo, fazendo com que o mesmo reconheça o conteúdo em sua própria realidade e veja que o ensino vai além de apenas uma "descrição".

Partindo deste pressuposto, é constante a presença de exemplos de ensino na narrativa dos colaboradores, que dissertam acerca de um ensino voltado para a realidade do aluno. A disciplina da Geografia para contribuir na formação plena da cidadania do aluno, precisa ser ensinada dentro de uma proposta pedagógica, estando aberta a atividades e técnicas que levem os alunos à discussão, à formação de ideias, deixando de lado a passividade. A escola, a disciplina e o professor não devem mais ser apenas transmissores de conhecimentos.

Os alunos, por sua vez, devem ter uma participação ativa, trazendo para a sala de aula a realidade vivida no seu dia a dia, e o professor e a escola deve ir até a realidade do aluno, promovendo aulas de campo. Dessa forma, espera-se que o ensino da Geografia, partindo da realidade do aluno, enfoque as diferentes visões de mundo e de lugar, fazendo com que o aluno participe de sua sociedade para que possa conhecer seu papel desde cedo.

Percebemos assim, a importância do Ensino da Geografia, levar os alunos ao entendimento da cidadania sem máscara, sabendo interpretar o mundo, participando das discussões socioeconômicas entre outras, com uma postura de análise e questionamentos diante da atual sociedade.

Para tanto, ao se trabalhar com essa disciplina, devemos ter claro que o ato de memorizar nomes, fatos e conceitos não motiva o aluno a aprender geografia, isso gera apenas mais um fardo de "tijolos" de conhecimento que carregam para vida. A realidade do aluno deve ser levada em consideração no momento da produção/transmissão do conhecimento geográfico, o que quer criar uma ponte entre o dia-a-dia da escola, dos alunos e do saber geográfico para despertar o interesse discente. Acreditase que práticas pedagógicas adotadas pelos professores são fundamentais para despertar o interesse do aluno, visto que a motivação e o interesse discente aumentam à medida que o mesmo se envolve com a escola e com a sociedade, rompendo com a tradição ainda muito presente no ensino da Geografia, de apenas descrevê-las. Analisar o conteúdo, gerar discussões, trazer para a sala de aula fatos e acontecimentos diários da sociedade são importantes metodologias a serem consideradas pelos professores de Geografia (Borges et al., 2011)..

A licenciatura da Geografia também enfrenta outra dificuldade: a não participação dos profissionais da área da educação na elaboração do currículo, sendo este elaborado por especialistas reconhecidos em suas áreas de conteúdos específicos de conhecimento dentro da Geografia. Um indicador disso é que vemos a escassa valorização dos cursos de licenciatura, sem uma distinção clara entre as duas habilitações, o que faz da licenciatura assim um mero apêndice à formação dos bacharéis (Pontuschka, 2010).

Neste contexto, se inclui também o incentivo à pesquisa, partindo da antiga ideia de que professor de escola básica não precisa pesquisar, pois seu papel é o de transmissor ou repassador do conhecimento científico. Porém, cabe ao professor despertar nos alunos uma atitude investigativa, em que a pesquisa acaba sendo um instrumento de ensino e conteúdo de aprendizagem (Pontuschka et. al., 2009). 


\subsection{Percepções da relação formação de professor e ensino de geografia}

Diversas correntes sobre o pensamento geográfico influenciaram grandemente sobre o ensino da Geografia Escolar, impondo características notáveis nas práticas pedagógicas escolares na atualidade. Contudo, vale ressaltar que a Geografia Escolar teve início no século XIX (Copatt \& Callai, 2018)

As reflexões sobre a importância do conteúdo no processo ensino-aprendizagem tem sido motivo de discussões sobre o modo de como se ensina e o que se ensina. Essas discussões ganham corpo com a teoria pedagógica que se propõe a trabalhar o conteúdo de maneira concreta e dinâmica, sendo o aluno o centro do processo educativo, o sujeito de sua própria aprendizagem, e o professor atuando seria o facilitador.

A partir da nova LDB/96, Lei de Diretrizes e Bases da Educação Nacional (LDBEN) 9.394/1996. Os conteúdos voltam a fazer parte das discussões através dos PCNs (Parâmetros Curriculares Nacionais), propondo uma mudança de enfoque aos conteúdos curriculares. Ao invés de um ensino em que o conteúdo é visto como fim em si mesmo, os PCNs propõem um ensino em que o conteúdo seja visto como meio para que os alunos desenvolvam capacidades que lhes permitam produzir e usufruir dos bens culturais, sociais e econômicos.

Embora se queira avançar, pois, no âmbito das discussões acadêmicas, muitas coisas estão resolvidas, a prática da sala de aula é ainda hoje assim, extremamente fragmentada em itens sem sentido, isolados e, no conjunto, sem o encadeamento que permite dar significado à Geografia escolar.

Para tanto, não basta ao professor ter domínio da matéria (conteúdos), torna-se necessário que o docente tenha a capacidade de pensar criticamente, desvendar os processos que permeiam a realidade social e que se coloque como sujeito transformador desta realidade. Compreende-se que a Geografia é uma disciplina de caráter estratégico na qual, inicialmente, a construção da aprendizagem é fundamentada na consideração da realidade vivenciada do cotidiano para se buscar diversos questionamentos, que levem o professor a realizar de forma adequada as explanações no interior de uma sala de aula.

De acordo com Pontuschka (2000), não é possível pensar o ensino e a aprendizagem da Geografia sem pensar que ela é parte integrante do contexto escolar. Nessa perspectiva, Kaercher (1999) afirma que,

"Juntamente com outras disciplinas escolares, a Geografia pode ser um instrumento valioso para elevar a criticidade dos alunos, pois trata de assuntos intrinsecamente polêmicos e políticos, quebrando a tendência secular da escola como algo tedioso e desligado do cotidiano" (Kaercher, 1999).

Um dos vestígios dos métodos antigos de ensinar é o foco em uma aprendizagem voltada para a descrição e memorização, sem avançar na análise do tema abordado de uma forma que os alunos não desenvolvem senso crítico. Esse método não é mais compatível com a proposta de geografia dos dias hoje, cabe ao professor buscar a melhor forma de ensinar essa disciplina.

Além de pesquisador, o professor é considerado um profissional com inúmeros saberes. Esta pluralidade de saberes é adquirida no contexto de sua vivencia, da formação inicial, adquirida nos cursos de licenciatura e decorrer de sua carreira docente. $\mathrm{O}$ processo de mediação esta intrinsicamente relacionado à identidade do professor, por ser adquiridos no decorrer da vida.

Seguindo o raciocínio de Tardif (2002) nota-se que "os diversos saberes docentes, associado a vivencia e identidade do professor dão lugar ao sentido de promover uma educação transformadora". Esse processo ocorre, porque o professor está lidando automaticamente com os problemas sociais que ocorrem cotidianamente.

Ao vivenciar tais problemas, surge a necessidade de contribuir de forma positiva com a sociedade, pois a identidade do professor constrói-se, pelo significado que o mesmo tem no seu cotidiano, a partir de seus valores, sua história de vida, 
modo de analisar o mundo, de seus valores, suas representações, sentimento, dentre outros fatores que aproxima o professor das problemáticas sociais cotidianas (Pimenta, 1999).

\section{Considerações Finais}

A Geografia vem acompanhando a evolução do homem, a partir do momento em que ela surgiu como disciplina escolar. Com as transformações ocorridas no mundo inteiro, a Geografia buscou acompanhar essas tendências, apesar de estar ainda muito atrelada aos moldes tradicionais enquanto disciplina.

Assim, necessita-se estar sempre em debate e sob-reflexões por parte daqueles que a estudam. Esta pesquisa procurou fazer um trabalho de análise metodológica do ensino de Geografia em escolas de ensino básico.

O professor deve ser um profissional inovador e criador. Claro que isso implica numa maior disponibilidade de tempo livre para o preparo e estudo dos temas a serem trabalhados com seus alunos. No entanto, as atuais condições de trabalho, a elevada carga horária, além de salário baixo explicam porque o professor continua, em regra geral, sendo um mero executor dos programas curriculares. Este fato ficou notório nas respostas dos professores.

Diante disso, o professor deve procurar desenvolver nos seus alunos a capacidade de questionar, duvidar e se posicionar diante da realidade de mundo. Se assim o fizer terá dado um importante passo para o aprendizado da Geografia. Nesta perspectiva, o estudante poderá perceber que o conhecimento não advém exclusivamente da assimilação de fenômenos e processos registrados em papéis. Pelo contrário, o conhecimento pode surgir da atitude de curiosidade frente ao mundo, face ao desconhecido.

Fica evidente a necessidade de se pensar uma educação institucionalizada que dê condições ao aluno, desde os primeiros contatos com a escola, de construir seu próprio conhecimento e aprender a lidar com as diversidades no ambiente escolar.

A Geografia é considerada uma das ciências mais importantes, uma vez que está presente em vários setores da sociedade, fazendo parte do cotidiano do homem ao longo da vida. Por conta disso é primordial que a escola situe o aluno desde cedo a conhecer noções básicas do ensino geográfico contribuindo para uma formação significativa do aluno.

Por fim, é possível trabalhar de maneira significativa o ensino da Geografia, pois esta é uma ciência e o seu conhecimento esta atrelada a política, a economia, a leitura de mundo que a criança tem com relação ao espaço, aos negócios, entre outros aspectos. Ressaltando a necessidade dos cursos de formação inicial, especificamente Pedagogia, desenvolver conceitos relativos a esta ciência/disciplina.

\section{Referências}

Andrade, R. B. (2018). Currículo e o ensino de geografia: orientações curriculares e educopédia na secretaria municipal de educação do Rio de Janeiro. Para Onde!?, 10(2), 36-44.

Bagno, M. (2001). Pesquisa na Escola. Edições Loyola.

Becker, F. (1994) O que é construtivismo? FDE.

Borges, J. V., Sartório, F. D. V., Souza, I. C., Pereira, T. B. e Falcão, W. S. (2011) A Geografia escolar e a formação para a cidadania: teoria e prática de professores dos municípios da grande Vitória, ES, Brasil. In: Anais do $12^{\circ}$ Encontro de Geógrafos da América Latina. San José, Costa Rica: Universidad de Costa Rica.

Brasil. Ministério da Educação. (1996). Lei de Diretrizes e Bases da Educação Nacional. Lei n. 9.394/96. http://www.planalto.gov.br/ccivil_03/Leis/L9394.

Brasil. Secretaria de Educação (2001). Média e Tecnológica Parâmetros curriculares nacionais: ensino fundamental. Brasília: MEC/SEMTEC, 2001.

Copatti, C., \& Callai, H. C. (2018). Tensões e intenções entre professor de geografia e livro didático na prática docente. Para Onde!?, $10(1), 52-59$.

Dezotti, M. S. \& Ortiz, A. C. M. (2010). O ensino de geografia em escolas de educação básica na cidade de Santa Maria, RS: uma análise metodológica. Disciplinarum Scientia. Série: Ciências Humanas, 11(1), 79-91. 
Research, Society and Development, v. 10, n. 11, e533101119825, 2021

(CC BY 4.0) | ISSN 2525-3409 | DOI: http://dx.doi.org/10.33448/rsd-v10i11.19825

Giovanni, A. C. C. Geografia em sala de aula: práticas e reflexões. Editora da Universidade/UFRGS.

Girotto, E. D. (2010). O lugar do ensino no processo de institucionalização da geografia no Brasil. Perspectiva Geográfica, (6), 166 -185.

Gonçalves, A. R. (2008). Geografia escolar: uma história sobre seus discursos pedagógicos. Estudos Geográficos: Revista Eletrônica de Geografia, 6(1), 135136.

Kaercher, N. A. (1999). Desafios e Utopias no Ensino de Geografia. EDUNISC.

Kaercher, N. A. (2009). O gato comeu a Geografia Crítica? Alguns obstáculos a superar no ensino-aprendizagem de Geografia. In: Pontuschka, N. N. e Oliveira, A. U. (orgs.). Geografia em perspectiva: ensino e pesquisa. Contexto.

Kneller, G. F. (1980). A Ciência como atividade humana. Ed. Zahar.

Konder, L. (1992). O Que é Dialética. Ed. Brasiliense.

Moreno-Hernández, M., López-Felipe, Y., \& Toledo-García, D. (2021). The Development of the Geographical Thought from the Teaching Activity Integrated with Geography Principles in Cuban Schools. Revista Electrónica Educare, 25(1), 470-491.

Oliveira, E. D., Souza, T. E, Almeida, M. F., \& Tavares, H. F. R. (2019). O papel e importância da ciência geográfica enquanto ferramenta de emancipação social: o contexto escolar. Revista de Geografia (Recife), 36(3), 12-29.

Paro, V. H. (2002). Gestão Democrática: qualidade em educação e inclusão social. Diário do Grande ABC: Diário na escola, p.3.

Pimenta, S. G. (1999). Formação de Professores: identidade e saberes da docência. In: Pimenta, S. G. (Org.). Saberes Pedagógicos e Atividade Docente. São Paulo: Cortez.

Pontuschka N. N., Paganelli, T. I \& Cacete, N. H. (2007). Para ensinar e aprender geografia. São Paulo: Cortez

Pontuschka, N. N. (2000). Geografia, representações sociais e escola pública. Terra Livre, 15, 145-154.

Pontuschka, N. N. (2010). Convergências e tensões na formação de professores de Geografia: a formação inicial do professor - debates. Olhar De Professor, 13(1), 37-46.

Pontuschka, N. N. et al. (2009). A formação docente e o ensino superior. In: Pontuschka N. N., Paganelli, T. I e Cacete. Para ensinar e aprender Geografia. São Paulo, Cortez.

Prodanov, C. C. \& Freitas, E. C. (2013). Metodologia do Trabalho Científico: Métodos e Técnicas da Pesquisa e do Trabalho Acadêmico, Feevale.

Richardson, R. J. (1985). Pesquisa Social: métodos e técnicas. Ed. Atlas.

Sousa, M. J. M., Silva, A. R. \& Magalhães, S. M. F. (2004). A cidade e a cidadania no ensino da geografia. Revista da Casa de Geografia de Sobral, 6(1), 5159.

Tardif, M. (2002). Saberes Docentes e Formação Profissional. Vozes.

Tonini, M. I. (Org.). (2011). O Ensino de Geografia e suas Concepções Curriculares. Ufrgs. 